Revista Kinesis, Santa Maria v.36, n.3, p.67-74, set-dez. 2018

Centro de Educação Física e Desportos - UFSM

DOI: $105902 / 2316546426041$

:Data de submissão: 06-03-2017

Data de Aceite: 29-11-2018

\title{
FATORES MOTIVACIONAIS PARA A PRÁTICA DE EDUCAÇÃO FÍSICA EM ALUNOS DO ENSINO MÉDIO DE DONA EUZÉBIA, MG
}

\author{
MOTIVATIONAL FACTORS FOR THE PRACTICE OF PHYSICAL EDUCATION IN STUDENTS OF THE MIDDLE SCHOOL OF \\ DONA EUZÉBIA, MG
}

ACTORES DE MOTIVACIÓN PARA LA PRÁCTICA DE LA EDUCACIÓN FÍSICA EN ESTUDIANTES DE EDUCACIÓN SECUNDARIA EN DONA EUZÉBIA, MG

Renan Antônio da Silva

lepp@rc.unesp.br

Instituto Universitário de Lisboa - ISCTE

\begin{abstract}
RESUMO
Este estudo objetivou-se em verificar quais fatores motivacionais são considerados mais importantes para a prática da Educação Física no Ensino Médio. Foi utilizado como instrumento a Escala de Motivos para a Prática Esportiva (EMPE). Participaram da investigação 30 estudantes do ensino médio com idade entre 15 a 18 anos, da Escola Estadual Domiciano Esteves, no município de Dona Euzébia, MG. Em ordem de importância, as respostas obtidas: Saúde, seguido de Condicionamento Físico (Muito Importantes), Técnica, Status, Afiliação, e Contexto (Importantes), e por último, Energia (Pouco Importante).
\end{abstract}

Palavras-Chave: Motivação; Educação Física; Ensino Médio

\section{ABSTRACT}

This study aimed to verify which motivational factors are considered most important for the practice of Physical Education in High School. The Scale of Motives for Sports Practice (EMPE) was used as instrument. 30 high school students between 15 and 18 years of age from the Domiciano Esteves State School, in the municipality of Dona Euzébia, MG, participated in the study. In order of importance, the answers obtained: Health, followed by Physical Conditioning (Very Important), Technique, Status, Affiliation, and Context (Important), and lastly Energy (Little Important).

Keywords: Motivation; Physical Education; Secondary Education

\section{RESUMEN}

Este estudio se basa en la observación de los factores motivacionales y es más importante para la práctica de la educación Física no Ensino Médio. Fue utilizado como instrumento a Escala de Motivos para una Práctica Esportiva (EMPE). Participaram da pesquisa 30 estudiantes del curso secundario entre 15 y 18 años, de la Escuela Estadual Domiciano Esteves, sin municipio de Dona Euzébia, MG. En el orden de importancia, como respuestas obtidas: Salud, seguido de Condicionamento Físico, Técnica, Estado, Afiliación, e Contexto (e Importante), e por último, Energia (Pouco Importante).

Palabras Clave: Motivación; Educación Física; Ensino Médio 


\section{Introdução}

O estudo da motivação, de acordo com Machado (2006), é muito importante para a compreensão de várias ocorrências que abrangem e compõem a prática esportiva, seja com crianças, jovens ou adultos, independendo inclusive do nível de capacidade em que se encontram seus praticantes. Encontra- se principalmente no ambiente escolar, onde há interação de todos os níveis de habilidades. Nesse sentido, Cozzani (apud Machado, 2006) afirma que se tratando de esporte de alto rendimento, o entendimento e a aplicação dos processos motivacionais são de grande importância para professores e técnicos, sendo eles os responsáveis pela instrução tanto dos atletas, quanto dos pais.

Samulski (2009) vê a motivação como um processo ativo, com a intenção de alcançar uma meta, o qual depende da interação de fatores intrínsecos e extrínsecos.

Discute- se os aspectos motivacionais das aulas de Educação Física no ensino médio mostrando a sua importância no processo de ensino aprendizagem, além da reflexão sobre o papel dos professores e sua colaboração para a motivação dos alunos. Aplicar conteúdos motivadores com objetivo de despertar nos alunos uma aproximação pela cultura corporal, como jogos, danças, lutas, ginástica e dos esportes. Entretanto, não se pode afirmar que a motivação depende exclusivamente da diversificação dos conteúdos, mas sim como um aspecto importante neste processo.

Nesse sentido, é possível afirmar que muitas situações que ocorrem no cotidiano das aulas podem fazer com que os alunos se sintam desmotivados, como as aulas repetitivas, a própria desmotivação dos professores, as condições de infraestrutura para a realização das aulas, entre outros aspectos. E com isso, interessa saber se as aulas de Educação Física no ensino médio estão sendo motivantes para os alunos.

A intenção de realizar esse estudo com alunos do ensino médio surgiu pelo visível desinteresse apresentado pelos alunos, o qual pode ser observado por uma participação não efetiva nas aulas práticas ministradas pelos professores. Torna-se necessário verificar se os alunos realmente gostam dos conteúdos propostos ou participam somente para obter avaliação favorável na disciplina. Com base nestas dúvidas, este estudo tem o interesse de trazer subsídios teóricos a respeito da motivação dos alunos na área prática da educação física.

O presente trabalho apresentou como principal objetivo verificar os fatores motivacionais presente nas aulas de Educação Física do ensino médio, de uma escola pública da cidade de Dona Euzébia- MG, assim como, analisar se os conteúdos desenvolvidos nas aulas de Educação Física possui relação com os aspectos motivacionais apresentados pelos alunos nas aulas ministradas. 


\section{Metodologia}

\subsection{Tipo de pesquisa}

Para a realização deste projeto foi realizada a pesquisa descritiva, sendo que na pesquisa descritiva realiza-se o estudo, a análise, o registro e a interpretação dos fatos do mundo físico sem a interferência do pesquisador. Será também realizada uma revisão bibliográfica, elaborada a partir de livros, revistas e artigos publicados na internet. Essa pesquisa auxilia na escolha de um método mais apropriado. Definindo desta forma que, a pesquisa bibliográfica é uma etapa fundamental em todo trabalho cientifico que influenciará todas as etapas de uma pesquisa, tendo como objetivo comparar estudos que possam chegar a uma conclusão ou dar novas linhas de pensamento dentro do tema abordado.

\subsection{Amostra}

Tendo como população noventa alunos do ensino médio de ambos os sexos, com idade entre 15 e 18 anos. A amostra compôs-se de trinta alunos da escola estadual, selecionados através de sorteio, sendo 10 de cada série e de ambos os sexos.

\subsection{Métodos para a coleta}

Para o estudo, foi utilizado um instrumento adaptado e validado no Brasil por Barroso e Krebs (2007), a EMPE (Escala de Motivos para Prática Esportiva) a partir do Participation Motivation Questionnaire (PMQ), desenvolvido nos Estados Unidos por Gill, Gross e Huddlestone (1983). Nesse instrumento, existe uma escala com valores de 0 a 10, orientando as respostas, em que o participante deve atribuir um valor para cada uma de suas 33 afirmações, sendo o o = nada importante, de 1 a 3 = pouco importante, de 4 a 6 = importante, de 7 a 9 = muito importante e 10 = totalmente importante. Estes itens, por sua vez, são agrupados posteriormente em sete fatores: Status (questões: 3, 13, 15, 21, 23, 27, e 30); Condicionamento físico (6, 16 e 26); Liberação de energia (4, 7, 14, 17, 18 e 31); Contexto (5, 9, 20, 29 e 33) Aperfeiçoamento técnico (1, 10, 25 e 28); Afiliação ( 2, 8, 12, 19 e 24) e Saúde (11, 22 e 32). 


\section{Análise De Dados}

A tabela 1 apresenta os resultados das sete categorias motivacionais do grupo em geral. Os resultados aqui mostrados serão discutidos de acordo com os objetivos do estudo.

Tabela 01 - Descrição das sete categorias motivacionais do grupo em geral $(\mathbf{n}=\mathbf{3 0})$.

\begin{tabular}{llllll}
\hline \multicolumn{1}{c}{ Categorias } & Média & Desvio Padrão & Mediana & Máx. & Mín. \\
\hline Status & 3,6 & 0,7 & 3,7 & 4,4 & 1,9 \\
Cond. Físico & 4,0 & 0,6 & 4,0 & 5,0 & 2,7 \\
Energia & 2,7 & 0,7 & 2,6 & 4,0 & 1,5 \\
Contexto & 3,0 & 0,7 & 2,7 & 4,8 & 2,0 \\
Técnica & 3,6 & 0,5 & 3,7 & 4,3 & 2,3 \\
Afiliação & 3,2 & 0,8 & 3,3 & 4,8 & 1,4 \\
Saúde & 4,4 & 0,5 & 4,3 & 5,0 & 3,3 \\
\hline \multicolumn{2}{c}{ Fonte: Elaborado pela autora inspirado em BESEN (2010) }
\end{tabular}

Fonte: Elaborado pela autora inspirado em BESEN (2010)

Apesar dos valores alcançados, todos os fatores motivacionais são considerados “importantes" ou "muito importantes" conforme o protocolo do EMPE. Ao analisar a tabela 1, percebe-se que o fator motivacional de maior importância entre os estudantes do ensino médio foi "Saúde" (média de 4,4), seguido de Condicionamento Físico com $(4,0)$, ambos classificados como "Muito Importantes". Técnica e Status $(3,6)$, Afiliação $(3,2)$ e Contexto $(3,0)$ foram considerados "Importantes" e o fator de menor motivação e classificado como "Pouco Importante" foi Energia $(2,7)$.

De acordo com Pisani et al (1990) o fator saúde pode ser considerado de ordem intrínseca, voltada para o ego, e classificados como motivos de sobrevivência . A saúde está entre os maiores motivos de ordem fisiológica, somente quando este é satisfeito o indivíduo passa a se preocupar com os demais.

Cid (2002) diz que condicionamento físico está completamente relacionado ao desempenho atlético, o que explica a grande importância que encontra tanto entre crianças quanto jovens e adultos envolvidos com atividade física, sendo, por exemplo, o motivo de prática mais importante.

A técnica de acordo com Pisani et al (1990), é um motivo intrínseco voltado ao ego, relacionado à competência. Já o Status se classifica como social, engloba os aspectos extrínsecos, da aprovação social por comparação direta e os intrínsecos do ego, os motivos desta dimensão se classificariam como sociais, relacionados à busca por prestígio, superação pessoal, desfrutar de privilégios e conviver com outras pessoas de destaque. A motivação por status costuma aumentar conforme a idade e o acúmulo de responsabilidades. 
Para Roberts et al (1986), afiliação trata-se de um motivo extrínseco de aprovação social, muito importante para crianças e adolescentes. Essa categoria esta mais presente nas faixas etárias inferiores e tendo mais importância com o passar dos anos.

Bronfenbrenner (1996) diz que o fator motivacional contexto refere-se ao espaço de interação de diferentes personalidades, que convivem em diversos valores e crenças. Caracteriza como micro sistema, dimensão que possibilita a interação face a face entre a pessoa em desenvolvimento focalizada, símbolos e objetos.

Para Dorsch et al (2001), a energia liberada é o potencial de desempenho e realização do individuo, é aquilo que nos leva a fazer algo, como praticar esportes. Em sentido psicológico, essa energia é o impulso da vontade, ou seja, a motivação. Considerando que a motivação é uma das manifestações da ativação, uma energia psicofísica, a prática esportiva se apresenta como contexto adequado para que, uma vez em excesso, a energia de ativação seja liberada de forma socialmente aceitável.

Algumas pesquisas utilizando o mesmo instrumento encontraram resultados semelhantes ao presente estudo quando se analisa os fatores de maior importância. Melo (2010) estudou a motivação para a prática esportiva em 100 adolescentes com idade de 12 a 18 anos, e verificou-se que os alunos de ambos os sexos atribuíram maior importância aos motivos relacionados à saúde. Maccari (2011), ao estudar 47 universitários da Universidade Federal de Santa Catarina que treinavam para apresentar a instituição, encontrou os fatores saúde e condicionamento físico como os mais importantes. Bertuol (2008), ao estudar os motivos da prática de 200 universitários na EFC (Educação Física Curricular), também verificou que os fatores saúde e condicionamento físico são os mais motivadores.

Ao analisar as questões do EMPE isoladamente, verificou-se que as questões 11 (onze) "eu quero manter a saúde" e 32 (trinta e dois) "eu quero melhorar ainda mais minha saúde" obtiveram na grande maioria das respostas o maior grau de importância "totalmente importante". Segundo Maslow (apud Tagliari et al, 1998), um motivo para isso poderia ser o fato de que pais e professores, realizam um trabalho de conscientização, influenciando os alunos a manter hábitos saudáveis, e praticar atividade física regularmente, mantendo um bom aspecto físico. 


\section{Conclusão}

Este trabalho teve como objetivo investigar quais os fatores motivacionais são considerados mais importantes para a prática da Educação Física no Ensino Médio A maioria dos alunos investigados considerou, com algum grau de importância, todas as dimensões motivacionais investigadas. Entretanto a categoria "Saúde" foi atribuída com maior grau de importância. Isto se deve ao fato dos pais e professores dos alunos estarem sempre conscientizando os alunos a manterem hábitos saudáveis, praticar atividades físicas, ter uma boa alimentação, boa qualidade de vida, se mantendo em um bom aspecto físico. E também através da mídia, como a televisão, internet, e entre outros que sempre matem a população informada. Logo em seguida está a categoria "Condicionamento físico", também considerada como totalmente importante, e logo após as categorias “Técnica”, "Status”, “Afiliação” e "Contexto”, consideradas importantes. Por ultimo está a categoria “Energia”, considerada de pouca importância pelos os alunos, onde a grande maioria possivelmente não gosta de liberar tensão, energia, ou seja, não senti muita emoção na prática.

Para melhorar ainda mais a motivação dos alunos, poderia acrescentar nas aulas de Educação Física, atividades e jogos voltados para a saúde e condicionamento físico. Uma forma para se alcançar esse objetivo seria a inserção de exercícios aeróbicos, circuitos, testes de velocidade e flexibilidade. Incentivando dessa forma ainda mais os alunos através de séries de exercícios que podem tornar a prática mais atraente e motivadora.

Segundo Lourenço (2015), homens necessitam de tempo e intensidade de prática de atividades físicas no lazer maior que as mulheres.

Estudar a motivação nas aulas de Educação Física é de extrema importância, já que a partir da pesquisa realizada, poderemos orientar melhor os alunos a prática da atividade física, da sua contribuição à saúde, melhorando a qualidade de vida, proporcionando hábitos alimentares saudáveis, diminuindo assim, a fuga precoce dos alunos das quadras, ou até, fazer com que os esforços despendidos nos jogos sejam potencializados, e, consequentemente, os mesmos possam atingir melhores resultados.

Os estudos corroboram em seus resultados na necessidade das aulas de EF, no Ensino Médio. Todavia, preconizam que essas aulas sejam melhor estruturadas em um planejamento curricular adequado, com mais tempo e frequência durante a semana, e que ocorram em ambientes que favoreçam para a sua realização.

Pode-se afirmar que os estudos acreditam na eficácia e importância das aulas de EF no 
Ensino Médio, fato evidenciado e reforçado nos principais resultados, no que se refere ao aumento do nível de atividade física, desenvolvimento de habilidades motoras e a manutenção da saúde destes jovens por meio das aulas de Educação Física.

É de grande relevância nos dias de hoje os resultados relacionados à motivação, já que em qualquer etapa de nossas vidas a motivação estará presente, podendo impulsionar nosso crescimento nas mais diversas esferas da vida, seja ela, pessoal, profissional e social.

De forma geral, percebeu-se uma lacuna de conhecimento a respeito do tema, mesmo considerando o pequeno aumento de publicações a partir de 2010, demonstrando que esse ainda apresenta-se insuficiente à produção científica abordando a temática Educação Física no Ensino Médio e a motivação pelos jovens. Deste modo, a realização de futuras investigações é requerida, no intuito de confirmar estes achados e impactar no aumento da produção cientifica e transferência destes resultados para o ambiente escolar, consequentemente contribuindo e colaborando para uma valorização e reconhecimento da área e dos professores de Educação Física.

\section{Referências Bibliográficas}

BERTUOL, Leonardo L. Motivos para a prática de educação física curricular dos estudantes da UFSC. Monografia (Licenciatura em Educação Física) - Centro de Desportos, Universidade Federal de Santa Catarina, Florianópolis, 2008.

BRONFENBRENNER, Urie. A ecologia do desenvolvimento humano: experimentos naturais e planejados. Porto Alegre: Artmed, 1996.

CID, Luís F. Alteração dos motivos para a prática desportiva das crianças e jovens. Revista Digital EF y Deportes, v.8, n.55, dezembro de 2002.

DORSCH, Friedrich; HÄCKER, Hartmut; STAPF, Kurt-Hermann. Dicionário de psicologia Dorsch. Tradução de Emmanuel Carneiro Leão e equipe. Petrópolis: Vozes, 2001.

KREBS, R.J. Desenvolvimento infantil: uma breve apresentação de algumas teorias emergentes. In: KREBS. R.J; FERREIRA, C. C. NETO (Orgs). Tópicos em desenvolvimento motor na infância e adolescência. Rio de Janeiro: LECSU, 2007. 
LEMES, Vanilson Batista, et al. Níveis de atividade física em dois modelos de aulas de Educação Física. Cinergis 16.4 (2016).

LOURENÇO, Camilo Luiz Monteiro, Thiago Ferreira de Sousa, and Markus Vinicius Nahas. Prática de atividades físicas no lazer como discriminador da autoavaliação positiva de saúde. Arquivos de Ciências do Esporte 1.1 (2015).

MACCARI, Bruna M. Motivos para prática competitiva de esportes coletivos femininos na Universidade Federal de Santa Catarina. Monografia (Licenciatura em Educação Física) Centro de Desportos, Universidade Federal de Santa Catarina, Florianópolis, 2011.

MACHADO, Afonso Antonio. Educação Física no ensino superior: Psicologia do esporte da educação física escolar ao esporte de alto nível. Rio de Janeiro: Guanabara, 2006.

MELO, Natália B. C. Motivação de adolescentes para a prática esportiva. Monografia (Escola de Educação Física) - Universidade Federal de Minas Gerais, Belo Horizonte, 2010.

MENEZES, Rafael de; VERENGUER, Rita de Cassia Garcia. Educação Física no ensino médio: O sucesso de uma proposta segundo os alunos. Revista Mackenzie de Educação Física e Esporte, Barueri, v. 5, p.99-107, 2006.

PERES, André Luis Xavier; MARCINKOWSKI, Bruno Borrin. A motivação dos alunos do ensino médio: Realização das aulas de educação física. Cinergis, Porto Alegre, v. 13, n. 4, p.26-33, dez. 2012.

PISANI et al. Psicologia geral. 11 ${ }^{\text {a }}$ ed. Porto Alegre: Vozes, 1990.

ROBERTS, Glyn C.; SPINK, Kevin S.; PEMBERTON, Cynthia L. Learning experiences in Sport Psychology. Champaign, IL (EUA): Human Kinetics, 1986.

SAMULSKI, Dietmar. Psicologia do esporte: Conceitos e novas Perspectivas. Barueri: Manole, 2009. 